\title{
Digital vascular imaging and selective renin sampling in evaluation of vascular anatomy in renal transplant recipients
}

\author{
G A KHOURY, J D IRVING, K FARRINGTON, Z VARGHESE, J W PERSAUD, P SWENY, \\ J F MOORHEAD, O N FERNANDO
}

\begin{abstract}
Sixty-five renal transplant recipients underwent digital vascular imaging of the graft and simultaneous selective venous sampling for plasma renin activity. Renal artery stenosis was found in seven patients but did not appear to be functionally important. Diffuse intrarenal arterial attenuation was found in seven patients and was associated with impaired graft function and perfusion; it may indicate chronic rejection. Lower pole hypoperfusion was found in nine patients without impaired graft function or perfusion; its clinical relevance is uncertain. Aneurysmal dilatation of the main renal artery was found in two patients. Severe hypertension was common in patients with these three major abnormalities, but a causal association between the abnormality and hypertension could rarely be inferred. It may be the abnormalities on digital vascular imaging, especially diffuse intrarenal arterial attenuation and lower pole hypoperfusion, are secondary to severe hypertension.

Digital vascular imaging with simultaneous selective venous sampling for plasma renin activity is useful in evaluating the vascular anatomy of the grafted kidney and in assessing any abnormality found. The
\end{abstract}

\footnotetext{
Department of Nephrology and Transplantation, Royal Free Hospital, London NW3 2QG

G A KHOURY, FRCS, surgical registrar

K FARRINGTON, MRCP, senior medical registrar

Z VARGHESE, PHD, principal biochemist

J W PERSAUD, BSC, senior biochemist

P SWENY, MD, MRCP, senior lecturer

J F MOORHEAD, FRCP, director

O N FERNANDO, FRCS, consultant surgeon

Radiology Department, Lewisham Hospital, London SE13 6LH J D IRVING, DMRD, consultant radiologist

Correspondence to: Dr G A Khoury.
}

combined procedure was well tolerated by all patients with no complications and no incidence of acute tubular dysfunction or proteinuria after the investigation.

\section{Introduction}

Until recently, imaging of the vasculature of renal transplants required formal arterial catheterisation and because of its invasive nature was used only in selected patients with severe uncontrollable hypertension. ${ }^{1}$ Digital vascular imaging, a new, less invasive method, permits quality imaging of the renal vasculature using smaller doses of contrast material that may be injected intravenously. ${ }^{2}$ Its place in the investigation of renal transplant recipients has yet to be evaluated.

In this study we combined venous sampling for renin with imaging of the renal vasculature to define the range of renal artery stenosis and its importance in an unselected group of renal transplant recipients. Renal artery stenosis in a patient with severe hypertension or poor graft function and perfusion, or both, may indicate correction of the stenosis by surgical means or other less invasive methods-for example, percutaneous transluminal angioplasty. ${ }^{3}$ Renal artery stenosis in the absence of serious haemodynamic consequences might indicate the need for serial imaging studies to define the natural history of the condition. An additional aim of the study was to identify patterns of vascular abnormality that may be associated with chronic rejection.

\section{Patients and methods}

We studied 65 unselected patients (39 male, 26 female) with functioning renal allografts. The protocol for the study was approved by the hospital ethical committee, and informed consent was obtained from all patients before the study. Ages ranged from 11 to 55 years. Renal transplantation had been carried out three months to 11 years before the study. Forty patients had received cadaveric transplants and 25 live donor kidneys. Immunosuppression consisted of azathioprine 
(1-2 $\mathrm{mg} / \mathrm{kg} /$ day) and prednisolone. No patient was receiving more than $0.5 \mathrm{mg}$ prednisolone $/ \mathrm{kg}$ at the time of the study, and most were taking 10-20 mg prednisolone daily.

Hospital records were examined for evidence of hypertension after transplantation. Patients were divided into four groups-namely, those who were normotensive; those with severe hypertension (patients who were receiving standard triple treatment-that is, diuretics, a beta-blocker, and a vasodilator or captopril); those with moderate hypertension (patients receiving only two antihypertensive agents-that is, a beta-blocker plus a diuretic); and those with mild hypertension (patients requiring only a single agent-that is, a betablocker or a diuretic).

Digital vascular imaging was carried out and interpreted by one of us without knowledge of the patient's renal function. All patients were receiving a free diet and were deliberately well hydrated over the the renal vein activity to the background peripheral plasma renin activity by the relation:

$$
\text { RSRI }=\frac{\text { PRA kidney }- \text { PRA peripheral blood }}{\text { PRA peripheral blood }}
$$

A value of 0.50 or above indicates hypersecretion of renin from the kidney studied ${ }^{4}$ and when associated with suppression of renin secretion from other sources predicts a favourable response to measures designed to reduce the hypersecretion of renin. ${ }^{56}$

Renal function after transplantation was estimated by serial measurements of plasma creatinine concentration and creatinine clearance. In most patients technetium-99m diethylene triamine penta-acetic acid renography was performed and the perfusion index calculated $^{7}$ as part of the routine assessment of graft function. The

Findings in patients with renal artery stenosis, diffuse intrarenal arterial attenuation, or lower pole hypoperfusion. (Renal: systemic renin index given in parentheses after plasma renin activity if $\geqslant 0.5$ )

\begin{tabular}{|c|c|c|c|c|c|c|c|c|}
\hline \multirow[b]{3}{*}{ Case No } & \multirow{3}{*}{$\begin{array}{c}\text { Grade of } \\
\text { hypertension }\end{array}$} & \multirow{3}{*}{$\begin{array}{c}\text { Plasma } \\
\text { creatinine } \\
(\mu \mathrm{mol} / \mathrm{l})\end{array}$} & \multirow{3}{*}{$\begin{array}{c}\text { Digital } \\
\text { vascular } \\
\text { imaging } \\
\text { perfusion } \\
\text { time (s) }\end{array}$} & \multirow{3}{*}{$\begin{array}{c}\text { DTPA } \\
\text { perfusion } \\
\text { index }\end{array}$} & \multicolumn{4}{|c|}{ Plasma renin activity $(\mathrm{nmol} / \mathrm{l} / \mathrm{h})$} \\
\hline & & & & & \multirow{2}{*}{ Peripheral } & \multirow{2}{*}{$\begin{array}{c}\text { Transplant } \\
\text { kidney }\end{array}$} & \multicolumn{2}{|c|}{ Native kidney } \\
\hline & & & & & & & Right & Left \\
\hline \multicolumn{9}{|c|}{ Patients with renal artery stenosis } \\
\hline 1 & Normotensive & 44 & 2 & ND & 0.5 & & $0 \cdot 8(0 \cdot 6)$ & $3 \cdot 1(5 \cdot 2)$ \\
\hline 2 & Moderate & 88 & 1.5 & 157 & $1 \cdot 1$ & $3 \cdot 5(2 \cdot 2)$ & $4 \cdot 2(2 \cdot 8)$ & $3.9(2.6)$ \\
\hline 3 & Moderate & 141 & 1.5 & 63 & 3.9 & 3.9 & $10 \cdot 2(1 \cdot 6)$ & $11.2(1.9)$ \\
\hline 4 & Severe & 186 & 1.5 & 157 & 23.9 & $38 \cdot 5(0 \cdot 6)$ & ND & $58.5(1.4)$ \\
\hline 5 & Severe & 265 & 2 & 131 & $8 \cdot 8$ & $7 \cdot 2$ & $8 \cdot 1$ & $5 \cdot 2$ \\
\hline $\begin{array}{l}6 \\
7\end{array}$ & $\begin{array}{l}\text { Severe } \\
\text { Severe }\end{array}$ & $\begin{array}{r}168 \\
88\end{array}$ & ${ }_{2}^{\mathrm{ND}}$ & $\begin{array}{l}138 \\
\text { ND }\end{array}$ & $\begin{array}{r}1 \cdot 3 \\
40 \cdot 0\end{array}$ & $\begin{array}{l}8 \cdot 5(5 \cdot 5) \\
32 \cdot 3^{(2)}\end{array}$ & $\stackrel{1 \cdot 9}{\mathrm{ND}}$ & $\begin{array}{r}3.2(1.5) \\
100(1.5)\end{array}$ \\
\hline \multicolumn{9}{|c|}{ Patients with diffuse intrarenal arterial attenuation } \\
\hline 8 & Normotensive & 256 & 3 & 292 & 3.9 & $6.1(0 \cdot 6)$ & $7.3(0.9)$ & $6.9(0.8)$ \\
\hline 9 & Mild & 292 & 2 & 265 & $6 \cdot 1$ & 6.7 & $9.2(0.5)$ & 8.9 \\
\hline 10 & Moderate & 150 & 3 & 140 & 17.7 & $31 \cdot 5(0 \cdot 8)$ & $24 \cdot 5$ & $20 \cdot 8$ \\
\hline 12 & $\begin{array}{l}\text { Severe } \\
\text { Severe }\end{array}$ & 283 & $\begin{array}{l}4 \\
4\end{array}$ & 260 & $\begin{array}{l}100 \\
46 \cdot 2\end{array}$ & $\begin{array}{l}100 \\
53 \cdot 4\end{array}$ & $35 \cdot 2$ & $\begin{array}{r}100 \\
41.5\end{array}$ \\
\hline 13 & Severe & 230 & 4 & ND & $5 \cdot 7$ & 4.6 & $19 \cdot 2(2 \cdot 4)$ & $10 \cdot 4(0 \cdot 8)$ \\
\hline 14 & Severe & 221 & 2 & 220 & $27 \cdot 5$ & $35 \cdot 2$ & 21.5 & 20.8 \\
\hline \multicolumn{9}{|c|}{ Patients with lower pole hypoperfusion } \\
\hline & Normotensive & 124 & 1.5 & 140 & 2.5 & $2 \cdot 8$ & $3 \cdot 1$ & $5 \cdot 0(1 \cdot 0)$ \\
\hline 16 & Normotensive & 88 & 1.5 & 75 & 26 & 3.9 & 3.9 & \\
\hline 17 & Moderate & 124 & 1.5 & 100 & $2 \cdot 4$ & 1.8 & 2.5 & $1 \cdot 8$ \\
\hline 18 & Moderate & 106 & 2 & 90 & $14 \cdot 3$ & $21 \cdot 1$ & $18 \cdot 3$ & $15 \cdot 2$ \\
\hline 19 & $\begin{array}{l}\text { Severe } \\
\text { Severe }\end{array}$ & 133 & $\begin{array}{l}1.5 \\
1.5\end{array}$ & $\begin{array}{l}151 \\
109\end{array}$ & $\begin{array}{l}15.2 \\
30 \cdot 2\end{array}$ & $\begin{array}{ll}14 \cdot 2 \\
31 \cdot 9\end{array}$ & $23.6(0 \cdot 6)$ & $32 \cdot 0(1 \cdot 1)$ \\
\hline $\begin{array}{l}20 \\
21\end{array}$ & $\begin{array}{l}\text { Severe } \\
\text { Severe }\end{array}$ & $\begin{array}{l}106 \\
274\end{array}$ & $\begin{array}{c}1.5 \\
2\end{array}$ & $\begin{array}{l}109 \\
163\end{array}$ & $\begin{array}{l}30.2 \\
38.9\end{array}$ & $32 \cdot 8$ & $\begin{array}{l}42.6 \\
68.5\end{array}(0.8)$ & $18.4(0.7)$ \\
\hline 22 & Severe & 106 & $\mathrm{ND}$ & 230 & ND & ND & ND & ND \\
\hline 23 & Severe & 133 & 3 & 106 & $\mathrm{ND}$ & ND & ND & ND \\
\hline
\end{tabular}

$\mathrm{DTPA}=$ Diethylene triamine penta-acetic acid. $\mathrm{ND}=$ Not done.

Normal values: plasma creatinine concentration $60-120 \mu \mathrm{mol} / 1(0 \cdot 68-1.4 \mathrm{mg} / 100 \mathrm{ml})$; plasma renin activity $0 \cdot 18-2 \cdot 49 \mathrm{nmol} / 1 / \mathrm{h}$ $0 \cdot 24-3 \cdot 24 \mathrm{ng} / \mathrm{ml} / \mathrm{h}$ )

Conversion. SI to traditional units-Creatinine: $1 \mu \mathrm{mol} / 1 \approx 11.3 \mu \mathrm{g} / 100 \mathrm{ml}$. Plasma renin activity: $=1 \mathrm{nmol} / 1 / \mathrm{h} \approx 1.3 \mathrm{ng} / \mathrm{ml} / \mathrm{h}$.

period of the study. A size 6 French gauge polyethylene catheter was inserted into the contralateral femoral vein and advanced to permit sampling from the renal transplant vein and native kidneys. About $50 \mathrm{ml}$ contrast (iopamidol (Niopam), sodium meglumine ioxaglate (Hexabrix), or sodium diatrizoate (Urografin)) was power injected at a rate of $14 \mathrm{ml} / \mathrm{s}$ into the inferior vena cava after voluntary suspension of respiration. Video data from an image intensified fluoroscopy system, incorporating a caesium iodide low dose intensifier tube, was logarithmically processed using a Philips digital vascular imaging apparatus, digitised, and stored. This information was used as a mask, which was then subtracted from a series of images obtained at half second intervals to demonstrate the arteries of interest on arrival of the dye. Exposures were less than those for conventional arteriography. The rate of graft perfusion was calculated from the half second frames, taking zero as the time of arrival of contrast at the origin of the renal artery. The time to the maximum nephrogram was estimated visually to the nearest $0.5 \mathrm{~s}$.

Blood samples were collected for estimation of renin activity during the imaging procedure after 45 minutes of supine rest. Samples were taken from the femoral/external iliac vein (peripheral blood renin activity), from the origin of the renal transplant vein, and from the native renal veins. Samples were taken into tubes containing sodium salt of edetic acid on ice, centrifuged within two hours of collection, and stored at $-20^{\circ} \mathrm{C}$ until analysed in batches. Plasma renin activity was assayed by radioimmunoassay, using a commercially available kit (CIS Sorin Biomedica, Sorin, Italy). The results of the renin assay were expressed as nmol angiotensin I released/I plasma/h. Plasma renin activity (PRA) from the native and transplanted kidneys was expressed as the renal:systemic renin index (RSRI), which relates normal value for the perfusion index is up to 140 . Statistical methods used were Student's $t$ test for unpaired samples and the $\chi^{2}$ test with Yates's correction as appropriate.

\section{Results}

Renal artery stenosis defined as a $25 \%$ or greater narrowing of the main renal artery supplying the transplanted kidney was found in seven of the 65 patients studied. Diffuse intrarenal arterial attenuation in the presence of peripheral pruning of the vascular tree with loss of small cortical blood vessels was seen in seven. Lower pole hypoperfusion was seen in nine patients. In these the above changes were restricted to the lower pole, with impaired or absent filling of the ventral segmental artery. Aneurysmal dilatation occurred in two patients. In 39 patients the kidney appeared normal on imaging and in one patient the procedure was technically unsatisfactory. The figure shows the patterns seen on imaging.

Renal artery stenosis (table) was associated with an end to side anastomosis in three of the seven patients and with an end to end arterial anastomosis in four. None had a Carrel patch. All stenoses were of the short segment type at or near the anastomosis. A bruit was audible in only one patient (case 7). Proteinuria $(.0 .5 \mathrm{~g} / 24 \mathrm{~h}$ ) was not found in any of the seven patients. Hypertension was present in six of the patients $(86 \%)$; this incidence was similar to that in patients in whom imaging studies yielded normal results $(26 / 39(67 \%))$. Severe hypertension, however, was present in four of the patients with renal artery stenosis $\left(57^{\prime \prime}\right)$ compared with six of the $39(15 \%)$ in whom 
imaging yielded normal results; this difference was highly significant $\left(\chi^{2}=5 \cdot 365, p=0.02\right)$. There were no significant differences between the two groups of patients with respect to renal function as indicated by plasma creatinine concentration or renal perfusion as estimated by digital vascular imaging perfusion time or perfusion index as determined by diethylene triamine penta-acetic acid scanning. In none of the patients with renal artery stenosis was the transplanted kidney identified as the sole source of hypersecretion of renin. Two patients, however (cases 3 and 7), were unequivocally identified as having hypersecretion of renin from the native kidneys.

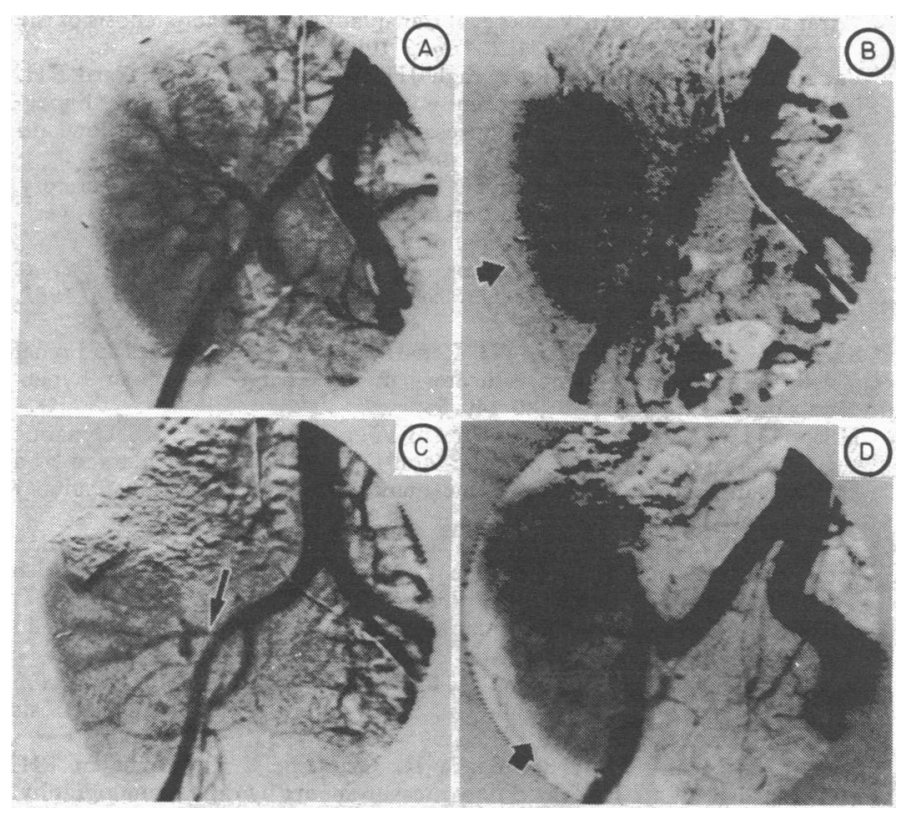

Patterns seen on digital vascular imaging. (A) Normal appearance of transplant kidney. (B) Diffuse intra-arterial attenuation. (C) Renal artery stenosis. (D) Lower pole hypoperfusion.

Diffuse intra-arterial attenuation-Although the incidence of hypertension in this group was similar to the incidence in the group with normal appearances on imaging, the incidence of severe hypertension was significantly higher $\left(\chi^{2}=5.365, p=0.02\right)$. The mean plasma creatinine concentration in this group $(242 \pm 48 \mu \mathrm{mol} / 1 \quad(2.7 \pm 0.5$ $\mathrm{mg} / 100 \mathrm{ml})$ ) was significantly higher $(\mathrm{p}<0.001)$ than that in patients with normal appearances $(124 \pm 42 \cdot 0 \mu \mathrm{mol} / 1(1.4 \pm 0.5 \mathrm{mg} / 100 \mathrm{ml})$ ). Renal perfusion was also significantly impaired in these patients compared with patients with normal findings on imaging (mean perfusion times $3.14 \pm 0.90 \mathrm{~s} v 1.53 \pm 0.16 \mathrm{~s} ; \mathrm{p}<0.001$ ). One patient in this group had an intrarenal aneurysm demonstrable on digital vascular imaging. One patient (case 10) was identified in whom the graft was the major source of hypersecretion of renin. Two patients (cases 9 and 13) had hypersecretion of renin from the native kidneys.

Lower pole hypoperfusion-Although the incidence of hypertension in this group was similar to that in the group with normal findings on digital vascular imaging, severe hypertension was again more common $\left(x^{2}=6.104, p=0.013\right)$. There were no differences between these two groups, however, in plasma creatinine concentrations or either of the estimates of graft perfusion. Four patients (cases 15, 19, 20,21) of the seven investigated had hypersecretion of renin from the native kidneys; one of these patients (case 15) was normotensive.

Aneurysmal dilatation of renal artery-two patients were found to have aneurysmal dilatation of the main transplant artery; both had a Carrel patch end to side anastomosis.

\section{Discussion}

Intravenous arteriography by digital vascular imaging was introduced for clinical trial in 1980. Its precise role in diagnostic radiology has yet to be determined, and clinical experience is limited. In the only published series in which it was used to investigate renal transplant recipients Hillman et al ${ }^{8}$ showed arterial stenosis and the state of the intrarenal circulation in 19 patients with no morbidity. In our study we catheterised the femoral vein by the Seldinger technique, instead of using the antecubital veins as used by Hillman et al, to allow for selective renin sampling and to prevent possible damage to arm veins, which may later be required for access to blood for haemodialysis.

An important indication for arteriography in renal transplant recipients is the detection of stenosis of the graft artery. Previously, arteriography was carried out only in selected hypertensive patients because of its invasive nature. The reported incidence of renal artery stenosis therefore approached $25 \%$ in these series. ${ }^{910}$ Stenosis of the graft artery occurred in only $11 \%$ of patients in this study, which included patients with normal blood pressure and mild hypertension. This figure may not represent the true incidence of renal artery stenosis after renal transplantation, since the patients studied may not have formed a random sample of the transplant population. An audible bruit over the transplant renal artery was found to be an unreliable sign of renal artery stenosis.

It is important not only to detect renal artery stenosis but also to determine whether the radiological abnormality has any functional importance-for example, impaired graft function or in causing hypertension. None of the seven patients with renal artery stenosis in this series had proteinuria, and graft function and perfusion did not differ from that in patients with normal results on imaging. In addition, though four of the patients were severely hypertensive, in none could the transplant kidney be definitely shown to be the cause of hypertension (table). This may indicate that renal artery stenosis (defined as over $25 \%$ narrowing) in this study was more of a radiological than a functional abnormality. Possibly, however, the influence of renin substrate on measurements of plasma renin activity and difficulties in interpreting these values (see below), rendered our method of localising renin hypersecretion too insensitive to detect graft hypersecretion in some cases, and that subtle changes in graft perfusion might have been detected had a specially adapted computer module ${ }^{11}$ been available for fitting to the imaging apparatus for measurement of graft perfusion.

Renal artery stenosis associated with severe hypertension, poor graft perfusion, and hypersecretion of renin by the graft may constitute an indication for surgery or percutaneous transluminal angioplasty, ${ }^{312}$ though in some cases graft stenosis has resolved spontaneously. ${ }^{13}$ Clearly, invasive intervention would not be indicated in any of the patients with renal artery stenosis in this series.

In the group of patients with diffuse intrarenal arterial attenuation graft function and perfusion were significantly impaired compared with the group of patients with normal findings on imaging. This suggests that this pattern of abnormality is important and may probably be taken as evidence of structural damage-for example, by chronic vascular rejection. Though four of the seven patients had severe hypertension and clear evidence of poor graft perfusion, in only one patient was the graft identified as the major source of renin. In two patients the native kidneys were identified as the major source of renin hypersecretion, suggesting that in these patients hypertension originating in the native kidneys may have caused arterial damage to the graft. Although the value of conventional angiography has been well documented in chronic rejection, ${ }^{14}{ }^{15}$ digital vascular imaging may be the preferred investigation because of its less invasive nature and the ease with which it may be combined with selective venous sampling for renin.

The importance of lower pole ischaemia is less clear. Impairment of lower pole perfusion was associated with hypertension, but renal function and perfusion were not significantly different from those in patients with normal appearances on imaging. In four patients hypersecretion by the native kidney could be shown (table), again suggesting arterial damage to the graft caused by hypertension originating in the native kidney.

The mechanism of production of the pattern of lower pole hypoperfusion on digital vascular imaging is uncertain. It might have resulted from kinking of the ventral segmental artery, but 
when the arteriograms were carefully examined most of these patients were found to have an intrarenal bifurcation of the main stem artery. Siegel $e t$ al $^{16}$ described three similar cases of "focal rejection" to the lower pole with histological confirmation in one. Biopsy specimens were not obtained from the upper poles in this study, and rejection may have affected the whole kidney.

The incidence of severe hypertension was significantly higher in patients with all major types of abnormality than in patients with normal appearances on imaging. Despite this it is clear that the association between the abnormality and hypertension cannot often be proved to be causal and that; especially in patients with diffuse intrarenal arterial attenuation and lower pole hypoperfusion, the abnormality is perhaps more likely to be secondary to severe hypertension.

Although measurement of plasma renin activity and the derivation of the renal:systemic renin index may be useful in localising hypersecretion of renin, there are certain difficulties with interpretation. The effect of antihypertensive agents is difficult to predict, but we did not see any ethical justification in stopping this treatment for the purposes of the study. This problem should not, however, interfere with the interpretation of the renal:systemic renin index or annul the importance of localising the hypersecretion of renin when possible.

A further difficulty is the stimulating effect of steroids on plasma renin substrate. ${ }^{1718}$ Although long term administration of steroids may increase the renin substrate concentration, the relative concentrations of renin and substrate in particular patients may be such that the kinetics of their reaction may be either zero order and substrate independent, or first order and dependent on substrate concentration. In the second case, therefore, raised plasma renin activity might be caused by increased renin secretion or increased substrate. Whichever of these predominates, raised plasma renin activity is still a most valuable indication of the ability of the system to generate hypertension. A substantial increase in the renin substrate, however, would have the effect of rendering the site of renin hypersecretion much more difficult to pinpoint by means of the renal:systemic renin index, which is based on plasma renin activity. This problem may be solved by adding excess substrate to the medium, thus establishing zero order kinetics. This permits the derivation of a substrate independent assessment of the plasma renin concentration. This method of measurement may be superior in cases in which localisation of renin hypersecretion is important, especially if substrate concentrations may be raised. The relative insensitivity of methods that use substrate dependent assays, such as estimates of plasma renin activity, does not invalidate results obtained in patients in whom localisation of renin hypersecretion was possible. The sensitivity of localisation may be further increased by measures designed to provoke renin secretion.

Good quality images are obtained by digital vascular imaging, often with smaller doses of contrast material than are necessary with conventional selective arteriography. This is an important consideration, since acute tubular dysfunction may occur with selective arteriography, particularly in patients with compromised renal function. ${ }^{19} 20$ In one study (G A Khoury et al, paper in preparation) no evidence of tubular damage was found after investigation with digital vascular imaging and none of the patients developed proteinuria. Since smaller doses of radiation are used with this type of imaging serial imaging may be used to assess progress of patients. Although none of our patients was investigated in the immediate postoperative period, digital vascular imaging will probably be of immense value in assessing the patency of the main transplant artery in the event of sudden anuria without fear of impairment of renal function. A final consideration is the low cost of both the contrast material and the films used in digital vascular imaging. In addition, considerable savings are obtained in the long term, since the procedure is carried out on an outpatient basis. Digital vascular imaging is an exciting new method for investigating renal transplant recipients, particularly as it may be combined with selective renin sampling.
We are grateful to Mrs Margaret Thomas and Sister Christine Pateman of the $x$ ray department, and to all the staff on Ward E3, Lewisham Hospital, for their kind and invaluable help.

\section{References}

1 Bachy C, Alexander GPJ, de Strihou C van Y. Hypertension after renal transplantation. $\mathrm{Br}$ Med f 1976;ii:1287-9.

${ }^{2}$ Hillman BJ, Ovitt TW, Nudelman S, et al. Digital video subtraction angiography of renal vascular abnormalities. Radiology $1981 ; 139: 277-80$.

${ }^{3}$ Harries-Jones EP, Wilson DR, Colapinto RF, Fenton SSA. Percutaneous transluminal angioplasty in a renal transplant recipient for stenosis of the grafted renal artery. Can Med Assoc F 1980;123:761-5.

- Vaughan ED Jr, Buhler FR, Laragh JH, Sealey JE, Baer L, Bard RH. Renovascular hypertension: renin measurements to indicate hypersecretion and contralateral suppression, estimate renal plasma flow and score for surgical correctability. Am $\mathcal{F}$ Med 1973;55:402-13.

${ }^{5}$ Laragh JH, Sealey JE, Vaughan ED Jr, et al. Renal venous renin secretory patterns before and after percutaneous transluminal angioplasty verification of mathematical diagnostic criteria. In: Zurukzoglu W, Papadimitriou M, Pyrpasopoulos M, Sion M, Zamboulis C. Proceedings of the VIIIth international congress of nephrology, Athens 1981. Basle: Karger, $1981: 457-61$.

- Stanley JC, Gewertz BL, Fry WJ. Renal: systemic renin indices and renal vein ratios as prognostic indicators in remedial renovascular hypertension. 7 Surg Res 1976;20:149-55.

${ }^{7}$ Hilson AJW, Maisey MN, Brown CB, Ogg CS, Bewick MS. Dynamic renal transplant imaging with Tc-99m DTPA (Sn), supplemented by a transplant perfusion index in the management of renal transplants. $\mathcal{F}$ Nucl Med 1978;19:994-1000.

${ }^{8}$ Hillman BJ, Zubowski CF, Ovitt TW, Ogden DA, Capp MP. Evaluation of potential renal donors and renal allograft recipients. Digital video subtraction angiography. Am $\mathcal{F}$ Radiol 1982;138:921-5.

- Lacombe M. Arterial stenosis complicating renal allotransplantation in man. Ann Surg 1975;181:283-8.

${ }^{10}$ Ricotta JJ, Schaff HV, Williams M, Rolley RT, Whelton PK, Harrington DM. Renal artery stenosis following transplantation; aetiology, diagnosis and prevention. Surgery 1978;84:595-602.

" Bursch JH, Hahne HJ, Brennecke R, Gronemeler D, Heintzen PH. Assessment of arterial blood flow measurements by digital angiography. Radiology $1981 ; 141: 39-47$.

12 Car D, Quin RQ, Hamilton DNH, Briggs JD, Junor BJR, Semple PF. Transluminal dilatation of transplant renal artery stenosis. $\mathrm{Br} \mathrm{Med} \mathcal{J}$ $1980 ; 281: 196-7$.

13 Vegter AJ, Krediet RT, Westra D, Tegzess AM. Reversible stenosis of the renal artery in cadaver kidney grafts; a report of three cases. Clin Nephrol $1981 ; 2: 102-6$

14 Castaneda-Zuniga W, Sibley R, Zollikofer C, et al. Renal artery aneurysms; an angiographic sign of transplant rejection. Radiology $1980 ; 136: 333-5$.

15 Hemingway AP, Allison DJ. Renal aneurysms in reject renal transplants. Br Med F 1980;281:1640-1.

${ }^{16}$ Siegel M, Glanz S, Gordon DH, Butt KM. Focal angiographic findings in renal transplant rejection. Urol Radiol $1981 ; 3: 97-100$.

17 Talwalkar RT, Kotchen TA, Welch WJ, Curtis JJ, Galla JM. Different mechanisms for the increased enzymatic activity of renin in plasma of patients with chronic renal failure and patients receiving glucocorticoid therapy. F Clin Endocrinol Metab 1980;50:989-93.

18 Konerup MJ. Pathophysiological and clinical aspects concerning the renin-angiotension system and the body sodium content in renal and post-renal transplant hypertension in humans. Scand $\mathcal{f}$ Urol Nephrol [Suppl] 1980;56:11-45.

19 D'Elia JA, Gleason RE, Alday M, et al. Nephrotoxicity from angiographic contrast material. $A m \mathcal{F}$ Med 1982;72:719-25.

${ }^{20}$ Lang EE, Foreman J, Schlegel JU, Leslie C, List A, McCormick P. The incidence of contrast induced acute tubular necrosis following arteriography. Radiology $1981 ; 138: 203-6$.

(Accepted 15 December 1982)

ONE HUNDRED YEARS AGO To the risks of the road, especially in the neighbourhood of large towns, on Sundays, we must add the dangers which arise from the perpetrators of the catapult nuisance. From the operations of lads who amuse themselves by loitering about suburban roads, and shooting stones from their formidable catapults, we have lately heard of several cases of injury to pedestrians. The offenders usually escape punishment, because no one takes the trouble to capture and prosecute them. The nuisance may seem a small thing to those who have not experienced it, but it is really time to put it down, for many persons have been injured by stones propelled with almost the force of a bullet. (British Medical Fournal 1883; i:921.) 